\title{
Apuntes sobre la izquierda cristiana y la secularización en la Argentina
}

\author{
José Zanca
}

Universidad de San Andrés / CONICET / CEHP-Universidad Nacional de San Martín

$\mathrm{E}^{\mathrm{n}}$ agosto de 1965 el semanario Confirmado informaba sobre una reunión llevada a cabo en el edificio del Seminario Metropolitano de Villa Devoto de la que habían participado más de setenta dirigentes, con el fin de unificar las diversas corrientes de la "izquierda cristiana". En la misma se afirmó que el proceso histórico llevaba al "derrumbe del capitalismo", y que el peronismo entraría, en breve, en un proceso de disgregación, dada la falta de una "doctrina coherente y científica que le permita sobrevivir". Más allá de su capacidad predictiva, la reunión había sido coordinada por tres figuras identificadas con el progresismo católico: el jesuita Alberto Silly, el filósofo Conrado Eggers Lan -recreador local del diálogo entre católicos y marxistas en la Facultad de Filosofía y Letras de la UBA- y Oscar Tiseyra, un militante de la Liga Humanista Universitaria que había publicado, un año antes, Cuba marxista: vista por un católico, reflejo de su viaje por la isla junto al sacerdote Héctor Ferreirós. ${ }^{1}$ En el año en que terminaba el Concilio Vaticano II (1962-1965), las relaciones entre el discurso religioso y las prácticas políticas parecían desacoplarse de sus tradicionales afinidades electivas. Si hasta fines de los cincuenta "lo católico" estaba asociado casi naturalmente al conservadurismo y se ubicaba a la derecha del espectro ideológico, los contertulios de Villa Devoto habían impresionado al articulista de Confirmado, quien sostenía que "la izquierda cristiana sigue avanzando en todos los medios intelectualizados y al nivel de los jóvenes sacerdotes" y la Compañía de Jesús "por supuesto, parece ser su aliado más importante". 2

Este ensayo explora la pertinencia de la categoría "izquierda cristiana", un intento de atrapar en una red conceptual un conjunto de iniciativas políticas, movimientos sociales y discursos teológicos. E indaga las vías que la conectan con el proceso de secularización. Propone, a tal fin, el análisis de las condiciones que hicieron posible la partición del campo católico en "izquierda" y "derecha", para lo cual la exposición se ha divido en tres apartados. El primero subraya la heterogeneidad del catolicismo y las características de sus divisiones; el segundo retoma el debate sobre la pertinencia de las coordenadas derecha/izquierda; y en el último se analiza la relación entre secularización y surgimiento de

\footnotetext{
2 "Jesuitas. La izquierda católica entra en escena", Confirmado, no 14, 6 de agosto de 1965, p. 11.

${ }^{1}$ Oscar Tiseyra, Cuba marxista: vista por un católico, Buenos Aires, Jorge Álvarez, 1964.
} 
una izquierda cristiana en la Argentina de la segunda posguerra.

\section{Las formas de la diversidad}

Las divisiones religiosas del siglo $\mathrm{xx}$ ponen en entredicho la pretendida homogeneidad del catolicismo argentino. No se trata solo de la obvia heterogeneidad de un movimiento que abarca diversas clases sociales, una extensa distribución geográfica, niveles jerárquicos internos y una clara segmentación por género. Se trata, sobre todo, de la pulsión de la jerarquía eclesiástica por reducir a sus fieles a la unidad, por convertir al catolicismo en una cultura. Desde fines del siglo XIX, cuando se consolidaron los estados modernos, el régimen de la cristiandad desapareció como ordenamiento político institucional. Sobrevivió, sin embargo, como horizonte de expectativas. La crisis abierta por la Primera Guerra Mundial, que puso en duda muchos de los pilares del liberalismo, les dio una nueva oportunidad a estos sueños restauradores. $\mathrm{O}$ al menos le devolvió a la jerarquía eclesiástica la expectativa de construir una muralla de organizaciones que contuviera, aislara, socializara y reprodujera a los laicos. Esas organizaciones debían impermeabilizarse de los contactos con la modernidad liberal y de cualquier contaminación con la política de partidos. Soñada como un brazo obediente de la jerarquía, la Acción Católica y todas las formaciones análogas que agrupaban a los laicos y contaban con el aval de los obispos, debían colaborar con la restauración de la sociedad cristiana.

En la Argentina, la cultura católica se expandió en forma vigorosa a partir de 1920. Los intelectuales confesionales se organizaron en los Cursos de Cultura Católica (CCC), de los que se desprendieron iniciativas como la revista Criterio, se vincularon con las vanguardias estéticas e incorporaron el catolicismo argentino al circuito de la cultura católica in- ternacional. ${ }^{3}$ Fracasó, sin embargo, el sueño de la jerarquía de mantener a los católicos por encima de las divisiones de la Argentina liberal. Por un lado, la militancia de Acción Católica y las principales figuras intelectuales estrecharon vínculos con el nacionalismo de derecha, en ascenso en los años de 1930 a 1940. Esta superposición de militancias ya había sido un problema en el viejo continente, cuando en 1926 el Vaticano condenó a la Acción Francesa, dirigida por Charles Maurras. Si bien la jerarquía protegió y alentó al nacionalismo argentino, también fijó límites para evitar la "contaminación" de las organizaciones del laicado. En ese sentido, pueden citarse numerosos ejemplos que ponen en evidencia las tensiones entre los pastores y su rebaño: el conflicto en el primer consejo de redacción de Criterio con su censor, el padre Zacarías de Vizcarra; los conflictos entre los CCC y la jerarquía durante toda la década de 1930 hasta su intervención en 1939; la expulsión de Leonardo Castellani de la Compañía de Jesús, después de que se presentara como candidato por la Alianza Libertadora Nacionalista. La Guerra Civil española, la Segunda Guerra Mundial y el peronismo generaron otra partición, con el surgimiento de un segmento de católicos antifascistas que exhibía cómo la política facciosa se introducía con éxito en la ciudadela católica y le imponía sus clivajes. ${ }^{4}$ El humanismo cristiano - vinculado a las figuras de Jacques Maritain, Emmanuel Mounier y el padre Louis-Joseph Lebret- le dio forma a esta división interna, que se fue consolidando a lo largo de la década de 1950. El Con-

\footnotetext{
3 José Zanca, "Los Cursos de Cultura Católica en los años veinte: apuntes sobre la secularización", Prismas. Revista de historia intelectual, $\mathrm{n}^{\circ} 16,2012$, pp. 199-202; Miranda Lida y Mariano Fabris (eds.), La revista Criterio y el siglo XX argentino. Religión, cultura y política, Buenos Aires, Prohistoria Ediciones, 2019.

${ }^{4}$ José Zanca, Cristianos antifascistas: conflictos en la cultura católica argentina, 1936-1959, Buenos Aires, Siglo XXI, 2013.
} 
cilio Vaticano II (1962-1965) hizo públicas estas diferencias. Entre los católicos de América Latina el evento se superpuso a la Revolución Cubana y a una nueva percepción de la secularización, compañera "necesaria" de la modernización y los sueños de desarrollo de los años sesenta. ${ }^{5}$

Esta breve exposición nos permite apreciar dos fenómenos: por un lado, la politización de los conflictos del catolicismo; por el otro, la búsqueda de discursos religiosos para legitimar las divisiones políticas. En el primer caso, la fragmentación del campo católico fue evidente a partir de los años cuarenta. Criterio, que se presentaba como una tribuna de debate en la que, en teoría, podía participar todo el catolicismo, dejó de serlo, a pesar de los denodados esfuerzos de su director, Gustavo Franceschi, por contener en su seno a nacionalistas y demócratas cristianos. Surgieron entonces Orden Cristiano, Estrada, Relación, Edición y los libros de la colección Nueva Cristiandad, de la colección Cuadernos Heroica y de la Editorial Difusión de los hermanos Luchía Puig. Iniciativas vinculadas al humanismo cristiano, que comenzaba a circular con vigor entre Europa y América Latina. La división se estabilizó y consolidó. Y en el período anterior al Concilio fue inocultable el enfrentamiento interno.

El segundo fenómeno implica una historia de la simbolización religiosa. Construir una teología que, en contextos determinados, sirviera para fundamentar las divisiones ideológico-políticas. Se dibujaron dos polos, opuestos y alternativos, que estuvieron disponibles a partir de la segunda mitad del siglo $\mathrm{xx}, \mathrm{y}$

\footnotetext{
${ }^{5}$ Loris Zanatta, Del estado liberal a la nación católica: iglesia y ejército en los orígenes del peronismo, 1930 1943, Buenos Aires, Universidad Nacional de Quilmes, 1996; Loris Zanatta, Perón y el mito de la nación católica: iglesia y ejército en los orígenes del peronismo (1943-1946), Sáenz Peña, Eduntref, 2013; Miranda Lida, Historia del catolicismo en la Argentina entre el siglo XIX y el XX, Buenos Aires, Siglo XXI, 2015.
}

que los intelectuales católicos utilizaron para simbolizar sus diferencias internas. Por un lado, una teología escatológica, por el otro, una teología de la encarnación. La primera se fundamentaba en un rechazo al mundo, gobernado por el eterno adversario, Satán. Lejos de acomodarse a la vida terrenal, rechazaba con énfasis la modernidad. La frase "Mi reino no es de este mundo" implicaba un compás de espera nutrido con una alta dosis de pesimismo antropológico. Sin la gracia divina, el hombre apenas se destacaba entre las bestias. La historia humana no era el escenario en el que se desplegaba la verdad. Por el contrario, la tradición escatológica se identificaba con la partición clásica, en la que el clivaje eterno/ temporal dividía lo puro de lo corrupto. La teología de la encarnación, por el contrario, presentaba la acción profana como una útil y necesaria colaboración humana en la construcción del Reino. Implicaba una antropología optimista, es decir, la posibilidad del progreso humano. Entre sus fuentes se destacaba el humanismo semita, que reconocía a la historia como un terreno en el que se desplegaba la vida de los hombres. Lo subrayaba el sacerdote y sociólogo santafesino Aldo Büntig, un "cristiano auténtico" no podía permanecer insensible ante los problemas urgentes: el hambre, el analfabetismo, la miseria. "Dios no creó al mundo como una cosa totalmente terminada, sino para que fuese su colaborador, en el sentido de continuar la obra creadora." ${ }^{\circ}$ Estas dos teologías -simbolizadas en Dios y Cristo, teocentrismo o cristocentrismo- fueron ejes de polémicas en la segunda mitad del siglo, y más allá de los debates eruditos en las revistas especializadas, esta división estaba presente en las publicaciones de carácter político y militante, así como en la

\footnotetext{
${ }^{6}$ Aldo J. Büntig y Carlos A. Bertone, Hechos, doctrinas sociales y liberación, Buenos Aires, Editorial Guadalupe, 1971, p. 16.
} 
estética de los años cincuenta y sesenta, basada en la idea de un Jesús histórico, comprometido, encarnado, rebelde e, incluso, armado con un fusil en su versión tercermundista. ${ }^{7}$

\section{Integralismo e intransigencia}

El haber reconocido que el catolicismo es un fenómeno heterogéneo no resuelve, sin embargo, el problema de la pertinencia de las categorías "izquierda y derecha". En la década de 1950, la partición del campo católico se hizo pública y, entre Europa y América Latina, comenzó a circular la figura del "católico progresista" -en oposición al "integrista"- y el chrétien de gauche. ${ }^{8} \mathrm{~A}$ fines de los setenta, el sociólogo francés Émile Poulat impugnó el uso de estas categorías dado que, desde su perspectiva, derecha e izquierda eran coordenadas de la modernidad liberal y por ende, una clasificación totalmente extranjera al mundo católico. Era una división inoperante porque no representaba clivajes autóctonos. En el subsuelo de esas aparentes divisiones, Poulat auscultaba una matriz persistente e inmarcesible: el integralismo. ${ }^{9}$ Este poseía cuatro características: era integral (rechazaba la división liberal, sacro/profano), romano (por su dependencia jerárquica), intransigente (por su rechazo incondicional a la modernidad) y social

\footnotetext{
${ }^{7}$ Vease el trabajo de Jean Laponce, sobre el uso de términos en función de la ubicación en el espectro ideológico, en Jean Laponce, "Dieu - à droite ou à gauche?", Canadian Journal of Political Science / Revue canadienne de science politique, vol. 3, n 2, 1970, pp. 257-274.

${ }^{8}$ René Rémond, "Droite et gauche dans le catholicisme français contemporain", Revue française de science politique, vol. 8, n 3, 1958, pp. 529-544. Sobre la “ excepcionalidad" del caso francés y la pertinencia del concepto de izquierda cristiana en Europa, véase Gerd-Rainer Horn y Emmanuel Gerard, Left Catholicism 1943-1955: Catholics and Society in Western Europe at the Point of Liberation, Lovaina, Leuven University Press, 2001.

${ }^{9}$ Émile Poulat, Une église ébranlée: changement, conflit et continuité de Pie XII à Jean-Paul II, París, Casterman, 1980.
}

(por su mirada crítica al capitalismo, al individualismo y a las leyes del mercado). El catolicismo era percibido como una cultura total, irreductible a una mera religión y refractario a la división propia de la modernidad liberal, entre privado y público. La matriz integralista se convirtió en una verdadera hermenéutica para interpretar el pensamiento católico, generando una renovada perspectiva para el abordaje de procesos históricos. En la Argentina de los años setenta era posible detectar el sustrato integralista tanto en las prácticas políticas de los grupos revolucionarios -surgidos, en muchos casos, en el seno de la sociabilidad religiosa-, como en las fuerzas represivas, asesoradas y reconfortadas por sacerdotes y teólogos que justificaron sus acciones en el marco de una espiritualidad de "cruzados", en la que sus crímenes se explicaban como parte de una guerra espiritual total entre las fuerzas del bien y del mal. ${ }^{10}$

La hipótesis de Poulat, que subsumía el cambio aparente a la vigencia matricial del integralismo, fue debatida desde distintas perspectivas. Los historiadores llamaron la atención sobre los profundos procesos de cambio que vivieron las iglesias de Europa y América Latina, que difícilmente podían reducirse a variaciones de una misma melodía religiosa. ${ }^{11}$ El politólogo Jean Marie Donegani, por su parte, sostuvo que si bien el Concilio Vaticano no había cambiado el anhelo integral del catolicismo -su deseo de romper

\footnotetext{
${ }^{10}$ Fortunato Malimacci, "Les Courants au sein du catholicisme argentin: continuités et ruptures", Archives de sciences sociales des religions, vol. 40, $\mathrm{n}^{\circ}$ 91, 1995, pp. 113-136; Luis Miguel Donatello, Catolicismo y montoneros: religión, política y desencanto, Buenos Aires, Manantial, 2010; Humberto Horacio Cucchetti, Combatientes de Perón, herederos de Cristo: peronismo, religión secular y organizaciones de cuadros, Buenos Aires, Prometeo Libros, 2010.

${ }^{11}$ François-André Isambert, “ Du Syllabus à Vatican II, ou les avatars de l'intransigeantisme. À propos de deux ouvrages d'Émile Poulat', Revue française de sociologie, vol. 19, n 4, 1978, pp. 603-612.
} 
la segmentación sacro/profano de la modernidad liberal-, sí había limitado su intransigencia, abriendo canales para negociar la noción de verdad con el objeto de hacerla compatible con la libertad del liberalismo. En definitiva, sostiene Donegani, excluir al catolicismo de las categorías derecha/izquierda por ser coordenadas de la modernidad liberal ocultaba que el concepto de integralismo también era nativo, pero de los sectores intransigentes del catolicismo que creían que la cultura católica debía ser impermeable a las influencias o intercambios con el exterior. ${ }^{12}$

A los efectos de la exploración histórica se impone una síntesis. Por un lado, Poulat deconstruye el secularismo. Política y religión, que aparecen como dos dominios separados y de lógicas internas incompatibles, en realidad funcionan como dos sistemas de simbolización. ${ }^{13}$ Dos sistemas culturales, dos textos a los que los sujetos recurren para explicar el mundo en un proceso de bricolaje en donde se une, se separa y se superpone. Por su parte, Donegani provee evidencia sobre la transigencia y la permeabilidad -y los debates que estas actitudes generaron- en el seno del catolicismo, en especial en la segunda mitad del siglo xx, cuando la secularización y los efectos del Concilio Vaticano II se expandieron por América Latina. En fin, estamos frente a una tensión entre las definiciones atentas a las perspectivas de los actores y las clasificaciones analíticas que intentan sobrevolar los supuestos de los protagonistas. El trabajo historiográfico deberá ponderar y poner a prueba, en cada caso, las posibles síntesis de esta disyuntiva.

\footnotetext{
12 Jean-Marie Donegani, La liberté de choisir: pluralisme religieux et pluralisme politique dans le catholicisme français contemporain, París, Presses de la Fondation Nationale des Sciences Politiques, 1993.

${ }_{13}$ Preferimos intercambiar el término liberal, utilizado por Poulat y Donegani, por secularismo, que define con más precisión una toma de posición frente a la religión en la sociedad moderna.
}

\section{Secularización interna y redefinición de la autoridad}

El proceso de secularización es un fenómeno multidimensional, multi-escalar y de una impactante diversidad geográfica. Por esa heterogeneidad toda una literatura sobre el tema ha solicitado eliminar el término, para evitar malentendidos. ${ }^{14}$ Sin embargo, es posible seguir utilizándolo para explicar el cambio religioso si en lugar de asociarlo con la desaparición de lo religioso se lo utiliza como sinónimo de reconfiguración de la autoridad religiosa. $\mathrm{Si}$, como dijimos al principio, uno de los objetivos de la jerarquía católica fue gobernar a partir de homogeneizar, la transformación de la autoridad religiosa fue tanto síntoma como consecuencia de la pluralización del campo confesional. Este declive, en el caso argentino, es sintomático desde los años cincuenta. Los primeros atisbos de conflicto se produjeron antes de la Segunda Guerra Mundial y luego con el peronismo. La crisis de 1954-1955 situó la distancia entre la jerarquía eclesiástica -que intentaba, denodadamente, aplacar el conflicto con el gobiernoy los laicos, de las más variadas posturas ideológicas, que se organizaron para colaborar con la campaña de panfletos y con el derrocamiento de Perón. Publicaciones que hasta ese momento habían sido una correa de trasmisión de las ideas de la jerarquía, como Criterio, se convirtieron en el terreno de ásperos debates, reflejando las divisiones del campo confesional. Surgieron otras publicaciones y grupos, representativos de los distintos segmentos en los que se iba fragmentando una verdadera opinión pública cristiana: la revista Comunidad, de la izquierda progre-

\footnotetext{
${ }^{14}$ Una síntesis de los debates contemporáneos sobre el tema en Diego Mauro e Ignacio Martínez, Secularización, Iglesia y política en Argentina. Balance teórico y síntesis histórica, Rosario, Facultad de Humanidades y Artes de la Universidad Nacional de Rosario, 2016.
} 
sista del Partido Demócrata Cristiano, la Liga Humanista universitaria; las revistas Tierra Nueva, Cristianismo y Revolución, Cristianismo y Sociedad, Cuadernos Humanistas, Nuevo Mundo, Latinoamérica, por señalar solo aquellas vinculadas a la izquierda. En algunos casos se trataba de iniciativas efímeras, de personajes que se repetían, pasando de un staff a otro. Teólogos católicos se superponían con protestantes, y la religión se anudaba, en forma natural, con las derivas de la política revolucionaria latinoamericana. ${ }^{15}$ Algo similar a lo que sucedía en el resto de la cultura de izquierda, con la que los cristianos abrían cada vez más vasos comunicantes. Esta pluralización del campo estuvo acompañada de su permeabilidad. El comunismo -la gran amenaza- comenzó a ser auscultado por intelectuales franceses y belgas, que encontraron en América Latina un espacio privilegiado para difundir sus ideas sobre la reforma social y la necesidad de reencontrar al catolicismo con la clase obrera. François Houtart, Louis-Joseph Lebret, Jean-Yves Calvez recorrieron Sudamérica traduciendo sus obras, dictando cursos, generando una nueva teología del Tercer Mundo. Esa permeabilidad con la modernidad - acompañada por la difusión de las ciencias sociales en las universidades confesionales y la renovación de la teología en seminarios y facultades tanto católicas como protestantes- permitió la aparición de una izquierda cristiana. Producto de una larga tradición de

\footnotetext{
${ }^{15}$ Sobre algunas de estas publicaciones, véase Gustavo Morello, Cristianismo y revolución: los orígenes intelectuales de la guerrilla argentina, Córdoba, Editorial de la Universidad Católica de Córdoba, 2003; Daniela Slipak, Las revistas montoneras: cómo la organización construyó su identidad a través de sus publicaciones, Buenos Aires, Siglo XXI, 2015, Esteban Campos, Cristianismo y revolución. El origen de Montoneros. Violencia, política y religión en los 60, Buenos Aires, Edhasa, 2016; José Zanca, Los intelectuales católicos y el fin de la cristiandad: 1955-1966, Buenos Aires, FCE, 2006, y Los humanistas universitarios: historia y memoria (1950-1966), Buenos Aires, EudEBA, 2018.
}

reformismo social católico, pero con un acento anti-capitalista proveniente de la tradición cultural francesa, se combinó con una valoración positiva de la secularización por parte de los sociólogos católicos de la década de 1960. El hombre contemporáneo podría ir más allá de la religión fosilizada y ritual. ${ }^{16}$ Opuestos a los sacramentos, sacerdotes y laicos tercermundistas fueron piezas clave para pensar el surgimiento de la nueva izquierda. Utilizaron, en forma alternativa, a Marx y a Teilhard de Chardin, al Che Guevara y a Camilo Torres, a Oscar Cullmann y a Harvey Cox. Carlos Mugica reivindicaba a quienes "desmitologizaban" el cristianismo, a los "profetas de nuestro tiempo": Hélder Cámara, Martin Luther King y Camilo Torres. "Estoy seguro" -sostenía- "de que el cristianismo de estos hombres habría modificado la valoración que Marx y Lenin hicieron de la religión. Para ellos, la fe en Cristo no sólo [no] es el opio de los pueblos, sino el impulso más profundo de su compromiso revolucionario". ${ }^{17}$ En otro registro, el sacerdote y cantante Alejandro Mayol sostuvo en una popular cumbia que "el pelado Lenin no estaba errado" y que el de la cristiandad era un "Dios prefabricado". ${ }^{18}$ En síntesis, la jerarquía que había abrazado al nacionalismo de derecha en los años treinta vio surgir bajo sus pies un cristianismo autónomo, anticlerical (en muchos casos), cristocéntrico, que reivindicaba la secularización social y desafiaba a la autoridad del Estado y de la misma iglesia.

\footnotetext{
${ }^{16}$ Michael Löwy, "El cristianismo de la liberación y la izquierda en Brasil", Anuario IEHS: Instituto de Estudios histórico-sociales, $\mathrm{n}^{\circ}$ 24, 2009, pp. 456-476.

${ }^{17}$ Carlos Mugica, Peronismo y cristianismo, Buenos Aires, Editorial Merlín, 1973. Artículo publicado originalmente en Cuadernos Panorama, $\mathrm{N}^{\mathrm{o}}$ 8, 21 de julio de 1970. Colección Meisegeier - Archivo Carlos Mugica, UNC, FOLIO CMI3 (7).

18 "A Dios rogando y con la guitarra cumbiando", Confirmado, $\mathrm{n}^{\mathrm{o}}$ 7, 18 de junio de 1965, p. 46.
} 
La idea de una "izquierda cristiana" parece ocluida por la historia del catolicismo de los años ochenta, en especial por la reconstrucción de la autoridad que desplegó el papa Juan Pablo II (1978-2005). Sin embargo, tal vez se pierda de vista que a partir de las teologías contestatarias y los movimientos tercermundistas el ejercicio de la hegemonía en la iglesia sufrió una fuerte reconfiguración. Su capacidad de mantener unido al conjunto de fieles a través de la ideología tuvo que redefinir sus bases y aceptar importantes transacciones con los diversos catolicismos latinoamericanos. Los cambios en el concepto de sacerdocio, pecado, autoridad religiosa, sacramentos, entre otros, mudaron la forma y los alcances en los que se podía ejercer el poder dentro de la iglesia. Más allá del uso de la coerción y el disciplinamiento, la resolución de la crisis de hegemonía abierta en los años de 1960 solo parece haber sido postergada por Karol Wojtyła.

\section{Palabras finales}

La pertinencia de la categoría "izquierda cristiana" nos interroga sobre el uso de dicotomías ideológicas en campos no estrictamente políticos. Su uso resulta productivo, al menos, por dos razones. Por un lado -sin rechazar una necesaria especialización historiográfica-, permite la convergencia de estudios sobre el catolicismo con la historia intelectual y política, al analizar los movimientos, publicaciones y órdenes religiosas con categorías análogas a las que se recurre para pensar a otros grupos políticos de izquierda y de derecha. Por otro lado, habilita la perspectiva de lo religioso como una forma de simbolización de lo político, donde las diferencias ideológicas se teologizan. Tomando distancia de las metanarrativas ilustradas, la presencia de lo religioso en lo político es una invitación a la deconstrucción de la esfera pública que, como señala el antropólogo Manuel Delgado, es un espacio imaginado como "aula y laboratorio", donde se reproduce una ideología de la neutralidad que en el fondo enmascara relaciones sociales y marcas identitarias. ${ }^{19}$

Sin negar la permanente flotación semántica del término "izquierda", la tensión entre categorías nativas y analíticas podría resolverse -al menos en este caso- a partir de una perspectiva histórica: sobre un fondo común, una cultura católica con una gramática de larga duración, en los años de 1960 se abrió a varias "teologías de izquierda". Desde el fin de la Segunda Guerra la heterogeneidad del catolicismo se hizo cada vez más aguda, y se debilitó la capacidad hegemónica de la jerarquía eclesiástica. La secularización interna del catolicismo habilitó la emergencia de una cultura cristiana de izquierda que desplegó una serie de oposiciones internas, una espiritualidad propia -es decir, un particular tipo de relación con los bienes de salvación-, y un conjunto de teologías que mantuvieron diversas y variadas relaciones con corrientes ideológicas y políticas vinculadas a la tradición contestataria, igualitarista y nacional-popular argentina.

\section{Bibliografía citada}

Büntig, Aldo y Carlos A. Bertone, Hechos, doctrinas sociales y liberación, Buenos Aires, Editorial Guadalupe, 1971.

Campos, Esteban, Cristianismo y revolución. El origen de Montoneros. Violencia, política y religión en los 60 , Buenos Aires, Edhasa, 2016.

Cucchetti, Humberto Horacio, Combatientes de Perón, herederos de Cristo: peronismo, religión secular y organizaciones de cuadros, Buenos Aires, Prometeo Libros, 2010.

Delgado, Manuel, El espacio público como ideología, Madrid, Libros de la Catarata, 2015.

${ }^{19}$ Manuel Delgado, El espacio público como ideología, Madrid, Libros de la Catarata, 2015. 
Donatello, Luis Miguel, Catolicismo y montoneros: religión, política y desencanto, Buenos Aires, Manantial, 2010.

Donegani, Jean-Marie, La liberté de choisir: pluralisme religieux et pluralisme politique dans le catholicisme français contemporain, París, Presses de la Fondation Nationale des Sciences Politiques, 1993.

Horn, Gerd-Rainer y Emmanuel Gerard, Left Catholicism 1943-1955: Catholics and Society in Western Europe at the Point of Liberation, Lovaina, Leuven University Press, 2001.

Isambert, François-André, “ Du Syllabus à Vatican II, ou les avatars de l'intransigeantisme. À propos de deux ouvrages d'Émile Poulat", Revue française de sociologie, vol. $19, n^{\circ} 4,1978$, pp. 603-612.

Laponce, Jean, “ Dieu - à droite ou à gauche ?", Canadian Journal of Political Science / Revue canadienne de science politique, vol. 3, nº 2, 1970, pp. 257-274.

Lida, Miranda y Mariano Fabris (eds.), La revista Criterio y el siglo XX argentino. Religión, cultura y política, Buenos Aires, Prohistoria Ediciones, 2019.

Lida, Miranda, Historia del catolicismo en la Argentina entre el siglo XIX y el XX, Buenos Aires, Siglo XXI, 2015.

Löwy, Michael, "El cristianismo de la liberación y la izquierda en Brasil", Anuario IEHS: Instituto de Estudios Histórico-Sociales, n ${ }^{\circ} 24,2009$, pp. 456-476.

Mallimaci, Fortunato, "Les Courants au sein du catholicisme argentin: continuités et ruptures", Archives de sciences sociales des religions, vol. 40, n 91, 1995, pp. 113-136.

Mauro, Diego e Ignacio Martínez, Secularización, Iglesia y política en Argentina. Balance teórico y síntesis histórica, Rosario, Facultad de Humanidades y Artes de la Universidad Nacional de Rosario, 2016.

\section{Resumen / Abstract}

\section{Apuntes sobre la izquierda cristiana y la secularización en la Argentina}

Este ensayo explora la pertinencia de la categoría "izquierda" para identificar un conjunto de iniciativas políticas, movimientos sociales y discursos teológicos propios del cristianismo de las décadas de 1960 y 1970 . Al mismo tiempo, indaga las vías que conectan el surgimiento de una izquierda cristiana con el proceso de secularización, en especial con la denominada "secularización interna" del catolicismo. El trabajo propone un recorrido por los debates en torno a la pertinencia de la díada en el catolicismo, justificando su uso por dos motivos. Por un lado, porque permite la confluencia de estudios sobre el
Morello, Gustavo, Cristianismo y revolución: los orígenes intelectuales de la guerrilla argentina, Córdoba, Editorial de la Universidad Católica de Córdoba, 2003.

Poulat, Émile, Une église ébranlée: changement, conflit et continuité de Pie XII à Jean-Paul II, París, Casterman, 1980.

Rémond, René, "Droite et gauche dans le catholicisme français contemporain", Revue française de science politique, vol. 8, n 3, 1958, pp. 529-544.

Slipak, Daniela, Las revistas montoneras: cómo la organización construyó su identidad a través de sus publicaciones, Buenos Aires, Siglo XXI, 2015.

Tiseyra, Oscar, Cuba marxista: vista por un católico, Buenos Aires, Jorge Álvarez, 1964.

Zanatta, Loris, Del estado liberal a la nación católica: iglesia y ejército en los orígenes del peronismo, 1930 1943, Buenos Aires, Universidad Nacional de Quilmes, 1996.

Perón y el mito de la nación católica: iglesia y ejército en los orígenes del peronismo (1943-1946), Sáenz Peña, Eduntref, 2013.

Zanca José, Los intelectuales católicos y el fin de la cristiandad: 1955-1966, Buenos Aires, FCE, 2006.

— , "Los Cursos de Cultura Católica en los años veinte: apuntes sobre la secularización", Prismas. Revista de historia intelectual, $\mathrm{n}^{\circ} 16,2012$.

Cristianos antifascistas: conflictos en la cultura católica argentina, 1936-1959, Buenos Aires, Siglo XXI, 2013.

- Los humanistas universitarios: historia y memoria (1950-1966), Buenos Aires, EUDEBA, 2018

\section{Notes on the Christian Left and secularization in Argentina}

This essay explores the relevance of the category "left" to identify a set of political initiatives, social movements, and theological discourses typical of Christianity in the 1960s and 1970s. At the same time, it investigates the pathways that connect the emergence of a Christian left with the process of secularization, especially with the so-called "internal secularization" of Catholicism. The work proposes a tour of the debates around the relevance of the dyad in Catholicism, justifying its use for two reasons. On the one hand, because it allows the confluence of studies on Catholicism with the rest of intellectual 
catolicismo con el resto de la historia intelectual y política, analizando movimientos, publicaciones y órdenes religiosas con categorías similares a las utilizadas para pensar a otros grupos políticos de izquierda y de derecha. Por otro lado, porque lo religioso puede ser entendido como una forma de simbolización de lo político, donde las diferencias ideológicas se teologizan.

Palabras clave: Secularización - Catolicismo Teología - Izquierda política and political history, analyzing movements, publications and religious orders with categories similar to those used to think of other political groups of left and right. On the other hand, because the religious can be understood as a form of symbolization of the political, where ideological differences are theologized.

Key words: Secularization - Catholicism - Theology - Left-wing politics 